\title{
Monetary and nonmonetary accountability following adverse medical events: options for Canadian patients
}

\author{
John E. Gray, William Beilby
}

$\infty \quad$ See related article page 889

$\mathrm{T}$ he analysis of the New Zealand data by Bismark and colleagues (see page 889 ) $^{1}$ reinforces the Canadian Medical Protective Association's long-held view that patients harmed in the course of receiving medical care seek redress based on a range of different motivations. Although the numbers may vary from one jurisdiction to another, the same underlying motivations are likely present regardless of the country involved or the nature of the medical liability system in place (no-fault or tort-based, enterprise or individual liability).

Somewhat contrary to the conclusions offered by Bismark and colleagues regarding medicolegal systems based on malpractice litigation, the Canadian medical liability system provides patients who are injured as a result of medical care with 3 potential responses: patient safety response, professional accountability response and tort-based litigation. Each response addresses different motivations and serves different purposes. In combination, they form the foundation of a balanced approach.

\section{Patient safety response}

This response deals with the need to learn from what occurred in order to prevent future similar events. The patient safety response must unfold in an environment in which everyone involved can share all of the information about what may have contributed to the event. The primary aim is to learn from adverse events and to improve health care delivery systems. Patient safety discussions can be speculative and should be used only to ensure that other patients do not experience a similar harm. To encourage full participation, patient safety information should not flow into the professional accountability or compensation responses. The primary onus for the patient safety response lies with the health care system, not the injured patient. Across Canada, health care authorities have established, or are establishing, welldefined patient safety reporting and investigation procedures.

\section{Professional accountability response}

Although most poor clinical outcomes are not the result of negligent care by health care professionals, this response deals with the accountability of the care provider and the need to ensure that the expected standard of care was provided. Within the Canadian context, this could include patient complaints to the hospital or to the regulatory authorities (colleges), inquests, human rights tribunals or action through other administrative bodies. The accountability response reinforces the responsibility of self-governing professions to ensure that standards are met and the public is protected. This response entails due process both for the patients and the health care professionals.

\section{Tort-based litigation}

The third response is that of compensation for injured patients, aimed largely at seeking restoration or mitigation of the consequences of the adverse event. Although some cases progress through a court system, a great many are resolved through settlement, often through alternate means of dispute resolution such as mediation. Unlike a no-fault system, a tort-based system also provides a means to promote professional accountability.

The selection of the avenue pursued reflects the particular motivations of the injured patient: a patient safety response to reduce the likelihood of repeating similar outcomes; a professional accountability mechanism to seek sanction or corrective action; and tort-based litigation to address restoration, compensation and, to a certain extent, accountability. The Canadian model provides options that respond to each of the diverse motivations described in the New Zealand analysis.

The multifaceted Canadian response mechanisms are supported by different disclosure and reporting regimes. Legally prescribed rules that protect quality assurance activities facilitate a learning environment that prioritizes patient safety. Legally prescribed reporting rules also protect the rights of all parties in both the professional accountability and litigation domains. However, regardless of the response the injured patient may choose to follow, the process always begins with physicians and other health care providers who exercise their obligation to disclose the clinical situation to the patient in a factual manner. Although this may, on occasion, be a difficult process for those involved, patients have a requirement to know about a poor clinical outcome whether it is related to their disease process or to their health care management. This is an important aspect of good clinical care in any jurisdiction or medical liability system.

This article has been peer reviewed.

Competing interests: None declared.

John Gray is Executive Director and Chief Executive Officer of the Canadian Medical Protective Association (CMPA). William Beilby is Associate Executive Director of the CMPA.

The CMPA is a not-for-profit mutual defence organization that provides medicolegal assistance and advice to Canadian physicians.

\section{REFERENCE}

I. Bismark M, Dauer E, Paterson R, et al. Accountability sought by patients following adverse events from medical care: the New Zealand experience. CMAJ 2006;175(8): 889-94.

Correspondence to: Barbara Wilson, Communications Advisor, Canadian Medical Protective Association, 875 Carling Ave., Ottawa ON KIS 5PI; fax 6I3 725-I300; bwilson@cmpa.org 